\title{
BMJ Open Interagency collaboration models for people with mental ill health in contact with the police: a systematic scoping review
}

\author{
Adwoa Parker, ${ }^{1}$ Arabella Scantlebury, ${ }^{2}$ Alison Booth, ${ }^{1}$ Jillian Catherine MacBryde, ${ }^{3}$ \\ William J Scott, ${ }^{4}$ Kath Wright, ${ }^{5}$ Catriona McDaid ${ }^{1}$
}

To cite: Parker A, Scantlebury A, Booth A, et al. Interagency collaboration models for people with mental ill health in contact with the police: a systematic scoping review. BMJ Open 2018;8:e019312. doi:10.1136/ bmjopen-2017-019312

- Prepublication history and additional material for this paper are available online. To view these files, please visit the journal online (http://dx.doi. org/10.1136/bmjopen-2017019312).

Received 24 August 2017 Revised 13 February 2018 Accepted 14 February 2018

Check for updates

${ }^{1}$ York Trials Unit, Department of Health Sciences, University of York, York, UK

${ }^{2}$ Institute of Health and Society, University of Newcastle,

Newcastle upon Tyne, UK

${ }^{3}$ York Management School, University of York, York, UK ${ }^{4}$ North Yorkshire Police, Newby Wiske Hall, Northallerton, UK

${ }^{5}$ Centre for Reviews and Dissemination, University of York, York, UK

Correspondence to

Dr Adwoa Parker;

adwoa.parker@york.ac.uk

\section{ABSTRACT}

Objective To identify existing evidence on interagency collaboration between law enforcement, emergency services, statutory services and third sector agencies regarding people with mental ill health.

Design Systematic scoping review. Scoping reviews map particular research areas to identify research gaps.

Data sources and eligibility ASSIA, CENTRAL, the Cochrane Library databases, Criminal Justice Abstracts, ERIC, Embase, MEDLINE, PsycINFO, PROSPERO and Social Care Online and Social Sciences Citation Index were searched up to 2017, as were grey literature and hand searches. Eligible articles were empirical evaluations or descriptions of models of interagency collaboration between the police and other agencies.

Study appraisal and synthesis Screening and data extraction were undertaken independently by two researchers. Arksey's framework was used to collate and map included studies.

Results One hundred and twenty-five studies were included. The majority of articles were of descriptions of models (28\%), mixed methods evaluations of models $(18 \%)$ and single service evaluations $(14 \%)$. The most frequently reported outcomes (52\%) were 'organisational or service level outcomes' (eg, arrest rates). Most articles (53\%) focused on adults with mental ill health, whereas others focused on adult offenders with mental ill health (17.4\%). Thirteen models of interagency collaboration were described, each involving between 2 and 13 agencies. Frequently reported models were 'prearrest diversion' of people with mental ill health (34\%), 'coresponse' involving joint response by police officers paired with mental health professionals (28.6\%) and 'jail diversion' following arrest (23.8\%).

Conclusions We identified 13 different interagency collaboration models catering for a range of mental healthrelated interactions. All but one of these models involved the police and mental health services or professionals. Several models have sufficient literature to warrant full systematic reviews of their effectiveness, whereas others need robust evaluation, by randomised controlled trial where appropriate. Future evaluations should focus on health-related outcomes and the impact on key stakeholders.
Strengths and limitations of this study

- This is the first, broad scoping review to map the evidence available for interagency collaboration models between the police and other agencies, for people with apparent mental ill health.

- We undertook rigorous searches for the available literature, including grey literature, led by an information specialist with input from the team, including a police officer.

- Two reviewers independently undertook study selection, and the data extraction and study coding was checked by a second researcher to ensure robustness in these processes.

- The lack of an assessment of study quality and synthesis of the findings means we were unable to make conclusions about the effectiveness of individual models.

\section{BACKGROUND}

Globally, there has been increasing policy and legislative focus on interagency collaboration for people with mental ill health coming into contact with the police and other statutory agencies such as healthcare providers. ${ }^{1-7}$ In recent decades in the UK and elsewhere, mental health legislation has required health departments to establish jointly agreed policies with other statutory agencies to manage people with a range of mental ill health. ${ }^{349}$

Interagency collaboration, also known as 'integrated', 'multiagency' or 'interprofessional' collaboration, ${ }^{10}$ 11 takes many forms ${ }^{12}$ ranging from a low level of joint decision making with limited shared resources to multifaceted, fully integrated services. ${ }^{13} 14$ Regardless of the form, interagency collaboration generally involves three core principles of information sharing, joint decision making and coordinated intervention. ${ }^{2}{ }^{15}$ Interagency collaborations involving the police aim to improve health and social care outcomes for 
individuals with mental ill health and the cost and effectiveness of services. ${ }^{16} 17$

A disproportionate number of people with mental ill health come into contact with police, who are often the first public service to interact with such individuals. Between $20 \%$ and $45 \%$ of police time is spent engaging with people experiencing mental ill health, as victims, witnesses or offenders. ${ }^{18}$ However, mental ill health is often unrecognised and poorly handled by the police, meaning that many people end up incarcerated rather than receiving appropriate treatment. ${ }^{19}$

There have been few systematic reviews of interagency collaboration models involving the police, with no current registered ongoing review; so the impacts, particularly health-related, of such models remain unclear. One review focused on guidance and research in the UK related to information-sharing practices within mental health services and the organisations they work in partnership with. ${ }^{20}$ Other reviews have focused on interagency working in general rather than law enforcement agencies. ${ }^{112} 2122$ The extent, range and nature of the available literature on interagency collaboration between the police and other agencies are unclear.

We therefore undertook a systematic scoping review of interagency collaboration models involving the police or other law enforcement organisations and emergency services, health and social care and third sector organisations, aimed at supporting people with mental ill health. Scoping reviews are used in complex areas or where there is no existing systematic review. They provide a map of the key concepts underpinning a research area and the main sources and types of evidence available'. ${ }^{23}$ It is then possible to identify areas where a full systematic review would be feasible and worthwhile, such as to capture the effectiveness of certain interventions on health outcomes.

\section{AIMS AND OBJECTIVES}

We aimed to identify and map the existing research evidence evaluating and describing interagency collaboration between the police or law enforcement and emergency services, health service, social care, education and third sector agencies for people who appear to be suffering from mental health disorder.

Our specific objectives were to identify and map the evidence available on:

1. models or mechanisms for interagency collaboration that have been described and/or evaluated

2. the broad areas and issues covered

3. views and experiences of the collaborative models.

\section{METHODS}

We undertook a systematic scoping review of the published evidence. This followed systematic review methodology, except for quality assessment of studies, and the evidence identified is mapped rather than the findings synthesised. ${ }^{24}$ The protocol was made publicly available a priori via our project website. ${ }^{25}$

\section{Inclusion and exclusion criteria}

Eligible studies were empirical evaluations or descriptions of models of interagency collaboration between the police and other organisations dealing with members of the public of any age appearing to suffer from mental disorder, mental vulnerability or learning disability. We include all terms used to describe interagency working, ranging from active collaboration (eg, 'interagency' or interprofessional collaboration) to professionals or services working in parallel with limited collaboration between them (eg, 'multiagency' or 'multiprofessional' working) (see online supplementary appendix 1). In this manuscript, we predominantly use the term 'interagency'; however, 'multiagency' is used where this is the term used in the original papers. Evidence and international literature from Organisation for Economic Cooperation and Development countries were included. Studies with any or no comparator were included. All outcomes measured were eligible for inclusion.

We excluded studies undertaken in the prison setting since separate arrangements exist for prisons, non-English language studies, studies where the interagency collaboration was focused solely on substance abuse and interagency collaboration without the involvement of the police. Online supplementary appendix 1 lists the full inclusion and exclusion criteria.

\section{Search strategy}

The following electronic databases were searched from inception to March 2017 by an information specialist: ASSIA, CENTRAL, Cochrane Database of Systematic Reviews, Database of Abstracts of Reviews of Effects, Criminal Justice Abstracts, ERIC, MEDLINE, Embase, PsycINFO, Social Care Online and Social Sciences Citation Index. The Cochrane Effective Practice and Organisation of Care and PROSPERO were searched for relevant reviews.

The search strategy for ASSIA is provided in online supplementary appendix 2 ; the complete search strategies are available from the authors on request. Searches were comprehensive and broadly combined domain terms and their associations for 'interagency' and 'police' and 'mental health'. 'Google Advanced Search' was used to identify documents and the websites of organisations such as the Centre for Mental Health, Crisis Care Concordat, National Health Services England and the Society for Evidence-Based Policing. We contacted the UK College of Policing for relevant evaluations. The reference lists of eligible studies were hand searched.

\section{Study selection and data extraction}

Search results were downloaded into Endnote, and duplicate references removed before titles and abstracts were screened. Study selection was undertaken independently by two researchers. Discrepancies were resolved by 
discussion or by recourse to a third researcher. Data extraction forms were developed and piloted. One researcher extracted data and classified the included studies, and this was checked by a second researcher. Discrepancies were resolved by discussion or by recourse to a third researcher. Data extraction forms were developed for primary/descriptive studies and for reviews. Information extracted included type of study, model of interagency collaboration, target audience, agencies involved, study setting and context, purpose of interagency collaboration, outcomes evaluated and whether stakeholder perspectives were evaluated.

\section{Strategy for collating, summarising and reporting the data}

We mapped the literature, following Arksey's ${ }^{26}$ framework. This involved developing a chart which outlined key variables of data to be extracted. Data were extracted from the original papers into the relevant sections of the chart and were subsequently sorted and shifted according to key issues and themes. This process is akin to a 'narrative review' in a standard systematic review. We first present basic numerical analysis of the extent, nature and distribution of the studies. We collated the geographical and chronological distribution of studies, agencies involved and the care recipient groups; research methods adopted; outcome measures reported and interagency models. We grouped studies according to the name of the interagency collaboration model and the definition of the model, as provided by the authors. We then used the terminology reported in the primary papers to code and categorise the different models. We present the studies grouped by the different models of interagency collaboration.

\section{RESULTS}

\section{Overview of included studies}

After deduplication, there were 2802 records; 340 fulltext articles were reviewed independently by two authors and 125 were included (figure 1 ).

The studies were from eight countries: Australia, ${ }^{27-41}$ Canada, ${ }^{42-50}$ Denmark, ${ }^{51}$ France, ${ }^{52}$ Ireland,${ }^{53}$ Netherlands, ${ }^{54} \mathrm{UK}^{55-91}$ and USA ${ }^{92-148}$; two multinational studies were undertaken in Australia, Canada and the USA. ${ }^{110} 149$ The majority of studies were from the USA (45\%) and the UK $(29 \%)$.

\section{Study design}

The study designs of the 125 included articles are given in table 1. Definitions for our classification of study designs are in online supplementary appendix 3 .

\section{Outcomes assessed}

There was a wide range of outcomes assessed, with some studies reporting multiple outcomes. Where this occurred, we report outcomes in all relevant categories (table 2); therefore, some studies are presented in multiple categories. The most frequently occurring outcomes (66 studies) were 'organisational or service level outcomes'.
The views and experiences of agency staff were investigated in 28 studies.

\section{Study population}

The majority of articles $(n=67)$ focused on adults, either diagnosed with or perceived to have a mental health problem, such as psychoses or severe mental illness (table 3). A number of articles focused on adult offenders with mental ill health $(\mathrm{n}=22)$ or adults with mental health and/or substance misuse problems $(n=7)$. Articles including children and youth generally focused on those who had been exposed to or victimised by violence $(n=4)$, child offenders with mental health and/or substance abuse problems $(n=3)$ or those with behavioural problems $(n=2)$. Three articles included children and adults.

\section{Models of interagency collaboration and agency composition}

Thirteen different models of interagency collaboration were described in the included articles, although there were often overlaps in agency composition. A number of articles reported on more than one model; therefore, papers are represented in each relevant section. The terminologies used to describe the different models of interagency collaboration were directly derived from the primary papers. Detailed descriptions of the models are provided in online supplementary appendix 4 .

The models identified involved collaborations between the police and a wide range of other services (table 4). The 'consultation model' and 'joint investigation training' only involved the police and mental health services; the remaining models were highly multidisciplinary involving a range of organisations. Information sharing agreements and court diversion models involved the widest combination of agencies. Across all collaborations with the police, mental health clinicians, mental health services and criminal justice agencies were the most frequently occurring partners.

\section{Prearrest diversion}

The most frequently reported model (43 articles) was prearrestdiversion, from Australia, ${ }^{293032333537}$ Canada, ${ }^{4244}$ the UK, ${ }^{60} 6774 \mathrm{USA}^{28} 93949698100102103113115-117123125126$ $\begin{array}{lllll}128 & 132-134 & 137 & 142 & 144 \quad 148\end{array}$ and two multinational articles involving Australia, Canada and the USA. ${ }^{110} 149$ Prearrest diversion models are described as involving police officers who had special mental health training, serving as the first-line police response to mental health crises in the community and acting as liaisons to the formal mental health system. The reported purpose of prearrest diversion models was to equip police officers to better manage situations involving people with mental health, substance abuse and/ or homelessness problems who became involved with the police and to offer treatment as an alternative to arrest. The most widely reported prearrest diversion model was the US-based Crisis Intervention Team (CIT) model. $^{28} 334298102103110113115117123125126132137144149$ CIT is a police-based first-responder programme for 


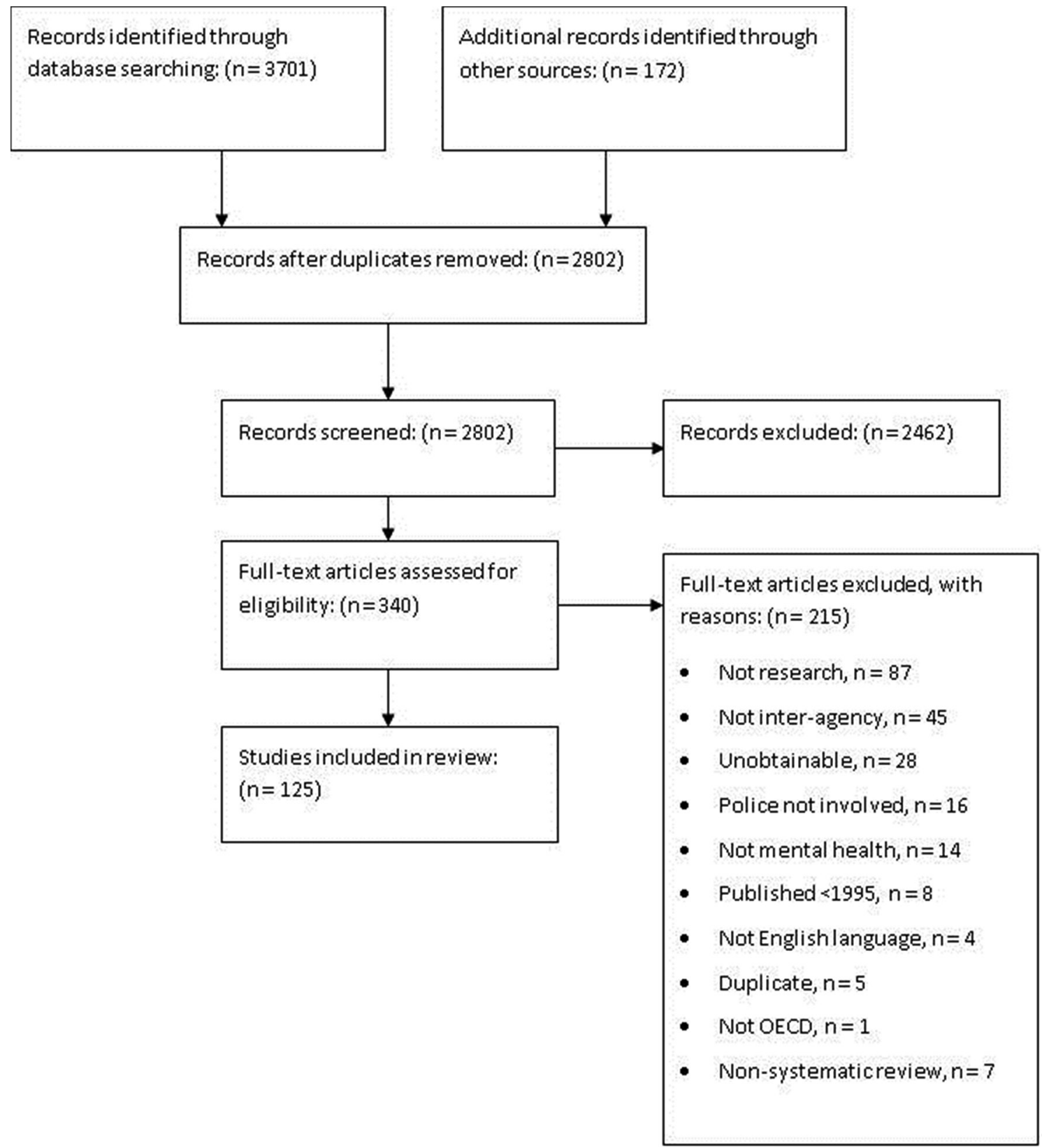

Figure 1 Flow chart of study selection process, adapted from PRISMA. ${ }^{166}$ OECD, Organisation for Economic Cooperation and Development; PRISMA, Preferred Reporting Items for Systematic Reviews and Meta-Analyses.

people in mental health crisis who come into contact with the police and provides police-based crisis intervention training. This model involved collaboration between police, emergency services and treatment providers such as clinical staff from local health departments, hospital emergency departments and specialised mental health services. CIT trained officers worked in partnership with mental health professionals to assist people with mental illness, family members and other police officers.

\section{Coresponse}

Coresponse models were reported in 36 articles, from Australia, ${ }^{27} 2831323440$ Canada, ${ }^{32} 424347-49 \mathrm{UK},{ }^{42} 687089$ USA $^{94100101104105110-112121130145150}$ and multinational studies involving Australia, Canada and the UK. ${ }^{110} 149$ In this model, a shared protocol paired specially trained police officers with mental health professionals to attend police call-outs involving people with mental ill health. The reported aims were to provide assistance to people in mental health crisis and prevent their unnecessary incarceration or hospitalisation. An example of this model is the UK-based 'Street Triage', 687089 where a dedicated police officer and psychiatric nurse together attend the scene of incidents requiring support for mental health needs. In Street Triage, the team did not provide the initial response to events. Rather, police call handlers allocated incidents to the Street Triage team if the incident required additional mental health support. 


\begin{tabular}{|c|c|c|}
\hline Study design & $\begin{array}{l}\text { No of studies } \\
(\%)\end{array}$ & Reference no \\
\hline Audit & $3(2.4)$ & 404183 \\
\hline Case study & $6(4.8)$ & 57697596136140 \\
\hline Scoping review & $1(0.8)$ & 42 \\
\hline Qualitative & $11(8.8)$ & $\begin{array}{l}2834474859818290 \\
132149167\end{array}$ \\
\hline Mixed methods & $23(18.4)$ & $\begin{array}{l}2729-31364951-53 \\
566165-677089104 \\
109118141142146 \\
147\end{array}$ \\
\hline $\begin{array}{l}\text { Controlled before } \\
\text { and after study }\end{array}$ & $15(12)$ & $\begin{array}{l}3954636468737988 \\
114120130131134 \\
144148\end{array}$ \\
\hline Service evaluation & $18(14.4)$ & $\begin{array}{l}353843727480 \\
85-87919394112116 \\
119121124137\end{array}$ \\
\hline Survey & $12(9.6)$ & $\begin{array}{l}58607684100105 \\
108110123135143 \\
150\end{array}$ \\
\hline $\begin{array}{l}\text { Description of } \\
\text { model }\end{array}$ & $35(28)$ & $\begin{array}{l}323337 \quad 44-465055 \\
627778929597-99 \\
101-103106107 \quad 111 \\
113115117122 \quad 125- \\
129133138139145\end{array}$ \\
\hline $\begin{array}{l}\text { Prospective } \\
\text { observational study }\end{array}$ & $1(0.8)$ & 71 \\
\hline
\end{tabular}

Telephone support to police colleagues attending a new incident was provided if the team were already busy.

Postbooking jail diversion

Thirty articles reported postbooking jail diversion programmes, from the UK ${ }^{58626465697173808283858688}$ and
USA. ${ }^{106} 107109114120126$ 131-133139140142148 This is a multiagency liaison scheme, comprising a rapid screening and mental health assessment of people arrested at the earliest point of contact with the criminal justice system, plus a mechanism for appropriate referral or diversion to health, treatment, social and community services. An example is Diversion at the Point of Arrest, ${ }^{85} 86$ a UK-based model in which people arrested and detained at police stations were assessed by a community psychiatric nurse, who then acted as the coordinator for the involvement of other mental healthcare workers and services as needed.

Information sharing agreement models

Information sharing agreement models were reported in 13 papers from Australia, ${ }^{36}$ Canada, ${ }^{45}$ Denmark,${ }^{51}$ France ${ }^{52}$ the UK ${ }^{5566} 6984$ and USA. ${ }^{99} 143$ In this model, information about people with mental ill health was shared between police and other agencies or between the individual with mental ill health and the police and other agencies. The reported aims of information models were to improve support to people with mental ill health, foster better relations between agencies and between the police and people with mental ill health, identify hard-to-find at risk people with mental ill health and protect the public from offenders with mental ill health. An example is the Multi-Agency Public Protection Arrangements (MAPPA) which aims to protect the public from harm by sexual and violent offenders, who may have mental ill health. ${ }^{84}$ Agency composition includes the police, other law enforcement agencies and mental health services. MAPPA agencies work together by identifying individuals who should be under MAPPA, managing such individuals, multiagency storing and sharing information about offenders, disclosure of information to the public about individual offenders in particular circumstances, risk assessment

Table 2 Outcomes assessed

\begin{tabular}{|c|c|c|}
\hline Outcomes assessed & $\begin{array}{l}\text { No of studies } \\
(\%)\end{array}$ & Reference no \\
\hline $\begin{array}{l}\text { Organisational/service level outcomes (eg, arrest } \\
\text { rates, diversion rates, mental health referrals, court } \\
\text { referrals and numbers of people under emergency } \\
\text { protective custody) }\end{array}$ & $66(52)$ & $\begin{array}{l}29-32353839414346495053545861-6468 \\
70-768083-8892939596100105107-110112 \\
114116118-121123124127130131133-137139 \\
140143144146147\end{array}$ \\
\hline $\begin{array}{l}\text { Views and experiences of agency staff (eg, police } \\
\text { officers) }\end{array}$ & $28(22)$ & $\begin{array}{l}28-31343647-49515256656670828994104 \\
109118123132141142146167\end{array}$ \\
\hline $\begin{array}{l}\text { Views and experiences of people in community (eg, } \\
\text { service users, families and carers) }\end{array}$ & $18(14.2)$ & $\begin{array}{l}29304347-49525356585965668990109118 \\
150\end{array}$ \\
\hline $\begin{array}{l}\text { Service user mental health outcomes (eg, } \\
\text { improvement in mood) }\end{array}$ & $7(5.5)$ & 58606280101118139 \\
\hline Cost effectiveness or wider economic costs & $3(2.4)$ & 276064 \\
\hline
\end{tabular}


Table 3 Care recipient group

\section{Care recipient group}

\section{No of studies (\%) Reference no}

Adults

Mental ill health

$67(53.2)$

27-36 39-42 4445 47-49 53546364 66-68

70717376818287899193949698100

$105108113116117119121123125-127$

$130132135137140142144145147-149$

\begin{tabular}{|c|c|c|}
\hline Mental health and/or substance misuse dual diagnosis & $7(5.6)$ & 435161112133134150 \\
\hline $\begin{array}{l}\text { Mental health, substance misuse dual diagnosis and/ } \\
\text { or homelessness }\end{array}$ & $3(2.4)$ & 107128141 \\
\hline Learning disabilities & $3(2.4)$ & 557879 \\
\hline Mental ill health and homelessness & $1(0.8)$ & 52 \\
\hline Offenders with mental illness & 22 & $\begin{array}{l}314650586272758083-868890106110 \\
111114120131143167\end{array}$ \\
\hline Offenders with learning disabilities & $1(0.8)$ & 69 \\
\hline $\begin{array}{l}\text { Individuals with pathological fixations, deemed to be } \\
\text { mentally ill }\end{array}$ & $4(3.2)$ & $\begin{array}{l}435161112133134150 \\
435161112133134150 \\
43516111213313415037387497\end{array}$ \\
\hline $\begin{array}{l}\text { Vulnerable adults, including mental health, learning } \\
\text { disabilities and other special needs }\end{array}$ & $5(4)$ & 5657596099 \\
\hline \multicolumn{3}{|l|}{ Children and young people } \\
\hline At risk children and youth & $4(3.2)$ & 92115118146 \\
\hline Offenders with learning disabilities & $1(0.8)$ & 65 \\
\hline $\begin{array}{l}\text { Offenders with mental health and/or substance abuse } \\
\text { problems }\end{array}$ & $3(2.4)$ & 109138139 \\
\hline Behavioural problems & $2(1.6)$ & 95136 \\
\hline $\begin{array}{l}\text { Children and adolescents who have been exposed to } \\
\text { or victimised by violence }\end{array}$ & $1(0.8)$ & 122 \\
\hline $\begin{array}{l}\text { Men, women, adolescents and older people with } \\
\text { mental health, learning disability or acquired brain } \\
\text { injury. }\end{array}$ & $1(0.8)$ & 77 \\
\hline \multicolumn{3}{|l|}{ Mixed adults and children } \\
\hline Children and families exposed to violence and trauma & $1(0.8)$ & 124 \\
\hline $\begin{array}{l}\text { People with Alzheimer's, children with autism and } \\
\text { Down syndrome }\end{array}$ & $1(0.8)$ & 129 \\
\hline $\begin{array}{l}\text { Men, women, adolescents and older people with } \\
\text { mental health, learning disability or acquired brain } \\
\text { injury }\end{array}$ & $1(0.8)$ & 77 \\
\hline
\end{tabular}

and management, multiagency meetings and case reviews.

\section{Court diversion models}

Eleven articles reported court diversion models from Canada, ${ }^{46}$ the UK, ${ }^{60} 63717587151$ Ireland ${ }^{53}$ and USA. ${ }^{73} 109135$ Offenders were 'diverted' from prosecution and into a specialised community-based service. Court diversion occurred following arrest while the individual was initially detained, during initial hearings, or while being assisted by pretrial services to offer community-based alternatives to standard prosecution. An example of such a service is 'liaison and diversion', which identifies and supports people with mental ill health, learning difficulties and other vulnerabilities in police stations and courts. ${ }^{60151}$

\section{Colocation}

Colocation was a model reported in five articles from Australia, ${ }^{28}$ the $\mathrm{UK}^{77}$ and USA. ${ }^{94} 100144$ In this model, mental health professionals were employed by police departments to provide on-site and telephone consultations to officers in the field. Another variant of the colocation model involved a dedicated police officer being based in an office within a mental health hospital; an example of this is the 'Police Liaison Forum'. ${ }^{77}$

Comprehensive systems model

Three papers from the USA reported a 'comprehensive systems' approach to reducing crime and arrests, three of which focused on reducing in school arrests. ${ }^{95} 118136$ Comprehensive systems models typically include policy 


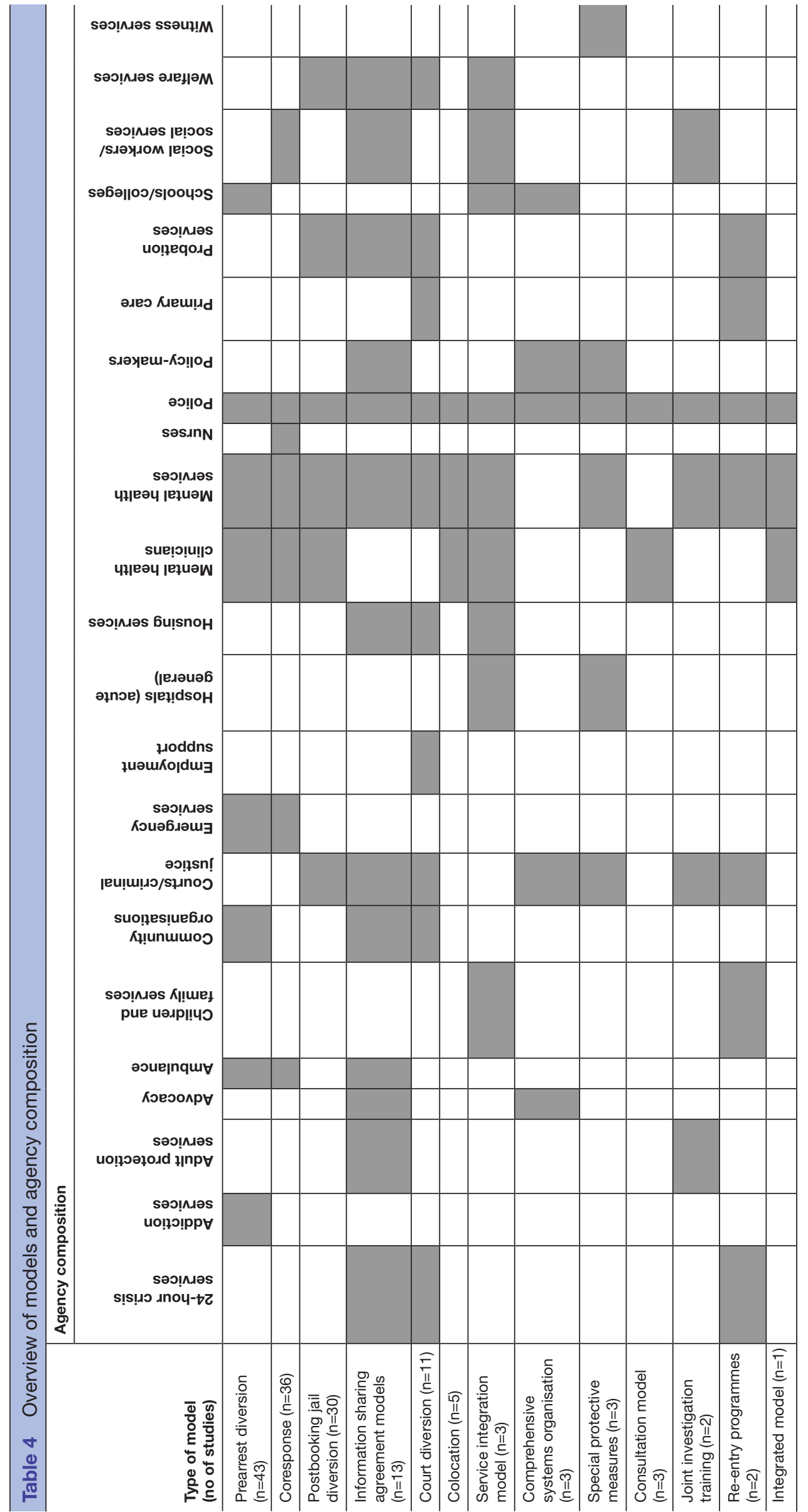


reform, multisystems coordination and changes to practice at multiple levels. An example was Project SOBEIT, ${ }^{118}$ which included six elements: (1) safe school environment, (2) alcohol and other drug and violence prevention and early intervention programmes, (3) school and community mental health preventive and treatment intervention services, (4) early childhood psychosocial and emotional development programmes, (5) educational reform and (6) safe school policies. In this model, school-based police officers worked with children, staff and external agencies to encourage prosocial behaviour and reduce drug use and criminalisation.

\section{Consultation model}

Three papers from Australia, ${ }^{41}$ the $\mathrm{UK}^{61}$ and $\mathrm{USA}^{97}$ reported on a 'consultation' model. In this model, police agencies accessed advice from mental health professionals when working with people with mental ill health. Typically, the advice was delivered over the telephone and generally aimed to maximise the resources provided by a specialist team and to assess and prevent criminal behaviour, protect life, arrest the perpetrator and protect property. An example is the Oldham Phone Triage/Rapid Assessment Interface, ${ }^{61}$ which consisted of a dedicated 24-hour telephone number for professional advice and assistance from, the local health service's psychiatric liaison service for local police officers.

\section{Service integration models}

Three articles from Canada, ${ }^{42}$ the Netherlands ${ }^{54}$ and the USA ${ }^{92}$ reported on 'service integration' models. The agencies involved were mental health providers, police officers, educational institutions and the children and family services (see table 4). The aims of these models were to integrate services by creating a network to bridge gaps between services, decrease arrest, decrease violence, improve educational attendance and completion and reduce symptoms of mental illness and psychological distress. Such models typically involve a network coordinator who provides active follow-up. An example of a service integration model is the "community-care networks'. ${ }^{54}$ A network coordinator (often community psychiatric nurse) received reports from network partners about any person of concern and gathered relevant information, established a plan of action and monitored implementation. Responsibility was transferred to the most appropriate agency as soon as possible.

\section{Special protective measures}

Three articles from the UK ${ }^{56}$ and USA ${ }^{122} 129$ focused on 'special protective measures', with the reported aim of identifying and protecting people with mental ill health, learning disabilities and other vulnerable people. An example of this was 'speaking up for justice', ${ }^{56}$ a collaboration between the police, the courts, hospitals and other agencies aimed at improving how vulnerable and intimidated witnesses were treated.
Joint investigation training

Two papers from the UK reported on a 'joint investigation training' model, ${ }^{57} 79$ which focused on adults with mental ill health, learning disabilities or other vulnerable adults who had crimes committed against them. This model involved joint mental health training for the police, social workers, mental health and adult protection services aimed at improving multiagency adult protection investigations and promoting collaborative working to support vulnerable adults. An example of such training is the 'Joint adult Protection Investigations' training. ${ }^{57}$

\section{Re-entry programmes}

Two articles from the USA ${ }^{127} 138$ reported on 're-entry' programmes, which aimed to assist individuals with mental illness to reintegrate into the community. This included institutional-based and community-based programmes serving individuals with mental illness following release from prison or hospitalisation. The 'Prime Time Project'138 involves a collaborative alliance with local police officers to involve young people with mental ill health who have been detained by the police and involves activities in the community training in job skills and other aspects of managing daily life.

\section{Integrated model}

One article reported an Early Psychosis Programme from Australia. ${ }^{39}$ In this model, police could become involved in the voluntary or involuntary admission process of people with mental ill health into the Early Psychosis Programme. The aim was to provide continuity, familiarity and support at an early stage throughout the health service to facilitate trust and reduce distress.

\section{DISCUSSION}

\section{Overview of main findings}

The scoping review identified 13 distinctive interagency collaboration models for people with mental ill health in contact with the police, mainly from the USA, UK and Australia. Although the majority of articles focused on adults with mental ill health, a substantial body of the literature focused on offenders with mental illness. The area most commonly covered was the relationship between the police and mental health services; unsurprising as this is a critical interface for the police service. However, it is noteworthy that several key agencies were not identified as agency collaborators. For example, the ambulance service was a named agency in only three models; yet in countries like the UK, the legal frameworks and guidance stipulate that people with mental ill health taken to a health-based place of safety should ideally be transported by ambulance. ${ }^{18} 152$ Additionally, 10 articles included people with dual diagnoses of mental health and substance abuse problems, yet addiction services featured as an agency in only one of the models. This may be indicative of conflicting priorities for services; however, there is 
potential for mutual benefit through greater interagency working.

Our review did not evaluate the risk of bias in the included studies, but in general, the study designs used are unlikely to provide robust evidence about effectiveness: there were no randomised controlled trials (RCTs). The main focus in the articles was the impact of the model on organisational level outcomes routinely collected by the police such as arrest and diversion rates, which they are required to collect. ${ }^{153}$ Several articles reported the views and experiences of members of the public coming into contact with the service as well as the different agencies involved. There are sufficient studies identified to justify development of focused questions for systematic review. These should include study designs relevant to the specific research question, such as qualitative studies if the focus of the review is to explore stakeholder perspectives and experimental designs if the aim is to explore effectiveness.

\section{Strengths and limitations}

A strength of our review is that the broad scope has facilitated mapping of the evidence available on interagency collaboration models between the police and other agencies, to appropriately manage people with apparent mental problems who come into contact with the police. The lack of an assessment of study quality and synthesis of the findings means we were unable to make conclusions about the effectiveness of individual models. However, this scoping review provides an overview of the literature not previously available. ${ }^{26}$

Identifying all available evidence on complex topics can be difficult as the relevant studies can be spread across numerous databases covering a range of disciplines. Furthermore, the key concepts may also be described using different terminology in each database so the search strategies need significant adaptation. ${ }^{154}$ Additionally, 'interagency' is a nebulous concept which has multiple definitions and is often interchanged with other terms, making studies on the topic difficult to identify. To address these issues, the search strategy was extensive and thorough and developed by an information specialist with input from members of the team including a police officer. We also undertook grey literature searches and hand searching to maximise retrieval.

Mapping focused on identifying distinctive models. Two reviewers independently undertook study selection and the data extraction and study coding was also checked by a second researcher to ensure robustness in these processes. However, the identification of the models inevitably has a subjective component. We have mitigated against this as far as possible through involvement of two researchers in the mapping as well as a providing examples and descriptions of each model. We assigned each study to a methodological grouping based on the description of the methods used, which may or may not have matched with the author's categorisation of the study.

\section{Comparison with existing literature}

To our knowledge, this is the first systematic scoping review to focus on interagency collaboration models for people with mental ill health in contact with the police. We identified no robust evaluations of models of interagency collaboration such as RCTs. Such a lack of evidence has been found in other fields assessing the evidence for interagency models. ${ }^{155}$ Our categorisation of the various interagency models, such as 'prearrest diversion', 'postbooking diversion' and 'court diversion', fits with the Sequential Intercept Model. ${ }^{156}$ The Sequential Intercept Model is a framework for conceptualising the range of community-based alternatives for people with mental ill health in contact with the criminal justice system. The model suggests a series of 'points of interception' at which interventions can be targeted to prevent individuals from entering or penetrating deeper into the criminal justice system. Our review is broader and considers interagency collaboration models outside the criminal justice system. For example, we highlight 'joint investigation training' or 'special protective' models as efforts that focus on people with mental illness as victims of crime or as vulnerable witnesses.

Although the majority of articles focused on adults with mental ill health, a number focused on offenders with mental illness; possibly because individuals with mental ill health are disproportionally more likely to be arrested and enter the criminal justice system. ${ }^{157158}$

\section{Knowledge gaps and implications for research, policy and professional practice}

While not all the models may be distinctive enough to make an RCT appropriate or feasible, there are a number of models where this approach would be appropriate. We identified an absence of high-quality evidence on effectiveness, despite the fact that models such as Street Triage and CIT are now routinely implemented within policing. Few evaluations considered the views of people with mental ill health or indeed the views and experiences of staff in the collaborating agencies.

Interagency collaboration models are complex interventions involving several interactive components and agencies. Existing guidance on the development and evaluation of theoretically informed, complex interventions may be useful in informing future development and evaluation of interagency models. ${ }^{159}$ More research is required to examine the effectiveness, cost effectiveness, barriers and benefits of interagency collaboration models. The latter is important for designing 'effective' models which might have significant benefit for healthcare. While there is significant political pressure on agencies to collaborate, ${ }^{18152160}$ at present, there is no clear understanding of the most effective or cost-effective ways of developing, implementing and delivering such models. Future models may require a more fundamental reassessment of the roles and functions of each agency and how they work together. Furthermore, legislative and policy changes and the speed with which they are implemented 
over time and in different jurisdictions can influence the availability and even preferences for certain models. For example, in the UK, changes in legislation such as the 2017 Police and Crime Act, ${ }^{161}$ which extends police powers under the Mental Health Act, are likely to impact on the adoption of certain models. Studies in this area should move from simple descriptions of models of care to prospective exploratory and experimental evaluations that include primary and secondary outcomes. We identified sufficient literature for some models such as prearrest diversion, coresponse and postbooking diversion which warrant more in-depth evaluation in a systematic review; some of this research is already underway with an upcoming systematic review focusing on the effectiveness of liaison and diversion, Street Triage and specialist staff embedded in police control rooms. ${ }^{162}$ Evaluations of the cost-effectiveness of such models would be important from a policy perspective, since one of the key drivers for interagency collaboration is to streamline services and improve efficiency ${ }^{160}$ particularly in the current UK context of austerity. ${ }^{163}$

Health services played a significant role in many of these models; however, only $5.5 \%$ of the articles assessed patient health outcomes, pointing to a need to identify the health-related benefits of interagency collaboration for patients and carers using robust methods. More work is also needed to develop conceptual clarity and frameworks around collaboration models encompassing people with mental ill health in contact with the police as suspects or perpetrators, as well as victims or vulnerable witnesses. Existing work in related areas could inform such work, such as a conceptual framework combining the concepts of primary care and integrated care to understand the complexity of integrated care ${ }^{164}$ Future studies could include the views of people with mental ill health in the development and evaluation of models. Ideally, researchers should specify the influence of the research context on their findings and explain any discrepancies between their findings and the findings of other studies, given the differences in context. This could involve the adoption of process evaluation methods, where guidance already exists to inform such work. ${ }^{165}$

\section{CONCLUSIONS}

We identified 13 different interagency collaboration models aimed at supporting people with mental ill health; including adults, children and different severities of condition and comorbidities. There were wide variations in the number of agencies involved within the models. All but one of these models included collaboration between the police and mental health professionals and/ or services and many of the identified models included other organisations relevant to the purpose of the collaboration. We have identified models where sufficient literature exists to warrant full systematic reviews to assess their effectiveness. We have also identified other areas which have highlighted the need for robust evaluation by RCT where appropriate. Important outcomes for future evaluations should include the impact on and experiences of the people the collaborations aim to assist, on staff from the agencies involved, as well as health-related outcomes for patients.

Acknowledgements We thank Kat Chatterton for assistance with sourcing interlibrary loans.

Contributors AP led the review and was responsible for writing the protocol, study selection, data extraction, grey literature and hand searches and writing the final report. KW devised the search strategies, carried out the literature searches and wrote the search methodology section of the paper. AP, AB and AS undertook study selection and data extraction. AP, AB, AS, CM, JCM and WJS inputted into the study conception and design. All the authors commented on the draft protocol and the final report. CM provided input at all stages, commented on all draft documents and had overall responsibility for the review. All authors read and approved the final manuscript.

Funding This work was supported by the Higher Education Funding Council for England (HEFCE) and the Home Office through the College of Policing (grant no J05).

Competing interests None declared.

Patient consent Not required.

Provenance and peer review Not commissioned; externally peer reviewed.

Data sharing statement The data extraction tables will be made available by placing a reasonable request with the lead author.

Open Access This is an Open Access article distributed in accordance with the Creative Commons Attribution Non Commercial (CC BY-NC 4.0) license, which permits others to distribute, remix, adapt, build upon this work non-commercially, and license their derivative works on different terms, provided the original work is properly cited and the use is non-commercial. See: http://creativecommons.org/ licenses/by-nc/4.0/

(C) Article author(s) (or their employer(s) unless otherwise stated in the text of the article) 2018. All rights reserved. No commercial use is permitted unless otherwise expressly granted.

\section{REFERENCES}

1. Department of Health and Concordat signatories. Improving outcomesfor people experiencingmental health crisis. London: HM Government, 2014.

2. Home Office. Multi-Agency Working and Information Sharing Project: Final Report. London, UK: Home Office, 2014.

3. UK Crown. Mental Health Act 1983. UK: The Stationery Office, 1983.

4. UK Crown. Mental Health Act 2007. UK: The Stationery Office, 2007.

5. Home Office. Supporting vulnerable people who encounter the police: A strategic guide for police forces and their partners. London, UK: Home Office, 2015.

6. Home Office, Department of Health. No Secrets: Guidance on developing and implementing multi-agency policies and procedures to protect vulnerable adults from abuse. London: Home Office, Department of Health, 2000.

7. Deaprtment of Health. Statement of Government Policy on Adult Safeguarding. London: Department of Health and Social Care, 2013.

8. National Mental Health Working Group. National safety priorities in mental health: a national plan for reducing harm. Canberra: Commonwealth of Australia, 2005. Publications approval number: 3725 (JN9187).

9. Metropolitan Police. Inter-agency joint working protocol for the management of mental health: Metropolitan Police. London: Metropolitan Police, 2011.

10. Robinson M, Atkinson M, Downing D. Supporting Theory Building in Integrated Services Research: ERIC, 2008.

11. Oliver C, Mooney A, Statham J. Integrated working: a review of the evidence. London: University of London, 2010.

12. Atkinson M, Jones M, Lamont E. Multi-agency working and its implications for practice. Reading: CFBT Education Trust, 2007. 
13. Darlington Y, Feeney JA, Rixon K. Interagency collaboration between child protection and mental health services: practices, attitudes and barriers. Child Abuse Negl 2005;29:1085-98.

14. Walter U, Petr C. A template for family-centered interagency collaboration. Families in Society: The Journal of Contemporary Social Services 2000;81:494-503

15. Home Office. Multi-Agency Working and Information Sharing Project Early Findings. London: Home Office, 2013.

16. Johnson P, Wistow G, Schulz R, et al. Interagency and interprofessional collaboration in community care: the interdependence of structures and values. $J$ Interprof Care 2003;17:70-83.

17. Paton F, Wright $\mathrm{K}$, Ayre $\mathrm{N}$, et al. Improving outcomes for people in mental health crisis: a rapid synthesis of the evidence for available models of care. Health Technol Assess 2016;20:1-162.

18. House of Commons Home Affairs Committee. Policing and mental health: Eleventh Report of Session 2014-15. London: The Stationery Office Limited, 2015.

19. Sainsbury Centre for Mental Health. Diversion: A better way for criminal justice and mental health. London: Nuffield Press, 2009.

20. Jenkins K. Information-sharing in mental health care provision: a review, 2014

21. Williams I. Offender health and social care: a review of the evidence on inter-agency collaboration. Health Soc Care Community 2009:17:573-80.

22. Phillips $\mathrm{C}$, Considine $\mathrm{M}$, Lewis $\mathrm{R}$. A review of audits and strategies produced by crime and disorder partnerships in 1999. Briefing Note. 8/00. London: Home Office, Research, Development and Statistics Directorate, Policing and Reducing Crime Unit, 2000

23. Mays N, Roberts E, Popay J. Synthesising research evidence. Studying the organisation and delivery of health services: Research methods, 2001:188-220.

24. Centre for Reviews and Dissemination. Systematic Reviews: CRD's Guidance for Undertaking Reviews in Healthcare. York: University of York, 2009.

25. Hughes-Morley A, Clarke A, MacBryde J, et al. What models or mechanisms for inter-agency collaboration between the police or law enforcement and other statutory agencies for people with mental problems have been evaluated, and what evidence is available on their effectiveness? A systematic scoping review. 2016 http://connectebp.org/wp-content/uploads/2016/09/Inter-AgencyScoping-Review-Protocol-v1-05.09.2016.pdf (accessed 17 Mar 2017).

26. Arksey H, O'Malley L. Scoping studies: towards a methodological framework. Int J Soc Res Methodol 2005;8:19-32.

27. Allen Consulting Group. Police, Ambulance and Clinical Early Response (PACER) Evaluation. Victoria: Allen Consulting Group 2012:1-66. Final Report.

28. Boscarato K, Lee S, Kroschel J, et al. Consumer experience of formal crisis-response services and preferred methods of crisis intervention. Int J Ment Health Nurs 2014;23:287-95.

29. Herrington V, Clifford K, Lawrence P, et al. The impact of the NSW police force mental health intervention team: final evaluation report. New South Wales: Charles Sturt University, 2009.

30. Herrington V, Cooperation I-agency. Inter-agency Cooperation and Joined-up Working in Police Responses to Persons with a Mental IIIness: Lessons from New South Wales. Policing 2012;6:388-97.

31. Hollander Y, Lee SJ, Tahtalian S, et al. Challenges Relating to the Interface Between Crisis Mental Health Clinicians and Police When Engaging with People with a Mental Illness. Psychiatry, Psychology and Law 2012;19:402-11.

32. Huppert D, Griffiths M. Police Mental Health Partnership project: Police Ambulance Crisis Emergency Response (PACER) model development. Australas Psychiatry 2015;23:520-3.

33. Laing R, Halsey R, Donohue D, et al. Application of a model for the development of a mental health service delivery collaboration between police and the health service. Issues Ment Health Nurs 2009;30:337-41.

34. McKenna B, Furness T, Oakes $\mathrm{J}$, et al. Police and mental health clinician partnership in response to mental health crisis: A qualitative study. Int J Ment Health Nurs 2015;24:386-93.

35. Meehan T, Stedman T. Trends in the use of Emergency Examination Orders in Queensland since the implementation of the Mental Health Intervention Project. Australas Psychiatry 2012;20:287-90.

36. Ogloff JRP, Thomas SDM, Luebbers S, et al. Policing Services With Mentally III People: Developing Greater Understanding and Best Practice. Aust Psychol 2013;48:57-68.

37. Pathé MT, Haworth DJ, Lowry TJ, et al. A model for managing the mentally ill fixated person at major events. Aust N Z J Psychiatry 2015;49:610-5.
38. Pathé MT, Lowry T, Haworth DJ, et al. Assessing and managing the threat posed by fixated persons in Australia. J Forens Psychiatry Psychol 2015;26:425-38.

39. Petrakis M, Penno S, Oxley J, et al. Early psychosis treatment in an integrated model within an adult mental health service. Eur Psychiatry 2012;27:483-8.

40. Victorian Auditor General's Report. Responding to mental health crisis in the community. Victorian Auditor General's Report. Victoria: Victorian Government Printer, 2009.

41. Webster S, Harrison L. The multidisciplinary approach to mental health crisis management: an Australian example. J Psychiatr Ment Health Nurs 2004:11:21-9.

42. Winters S, Magalhaes L, Kinsella EA. Interprofessional collaboration in mental health crisis response systems: a scoping review. Disabil Rehabil 2015;37:2212-24.

43. Baess E. Integrated Mobile Crisis Response Team (IMCRT): Review of pairing police with mental health outreach services. Victoria, BC: Vancouver Island Health Authority, 2005.

44. Cant I. The secondary family: the result of strong community partnering. Mental Health Review Journal 2007:12:30-3.

45. Coleman TG, Cotton DH. Reducing Risk and Improving Outcomes of Police Interactions with People with Mental IIIness. Journal of Police Crisis Negotiations 2010;10(1-2):39-57.

46. De Caire G. A wrap-around social service solution. Blue Line Magazine 2013;25:14.

47. Forchuk C, Jensen E, Martin M-L, et al. Psychiatric Crisis Services in Three Communities. Can J Commun Ment Health 2010;29(S5):73-86.

48. Kirst M, Francombe Pridham K, Narrandes R, et al. Examining implementation of mobile, police-mental health crisis intervention teams in a large urban center. J Ment Health 2015;24:369-74.

49. Kisely S, Campbell LA, Peddle S, et al. A controlled before-andafter evaluation of a mobile crisis partnership between mental health and police services in Nova Scotia. Can J Psychiatry 2010;55:662-8.

50. Swaminath RS, Mendonca JD, Vidal C, et al. Experiments in change: pretrial diversion of offenders with mental illness. Can $J$ Psychiatry 2002;47:450-8.

51. Sestoft D, Rasmussen MF, Vitus K, et al. The police, social services and psychiatry cooperation in Denmark--a new model of working practice between governmental sectors. A description of the concept, process, practice and experience. Int J Law Psychiatry 2014;37:370-5.

52. Girard V, Bonin JP, Tinland A, et al. Mental health outreach and street policing in the downtown of a large French city. Int J Law Psychiatry 2014;37:376-82.

53. Mental Health Commission and An Garda Siochana. Report of joint working group on mental health services and the police. Mental Health Commission and An Garda Siochana 2009:1-104.

54. Wierdsma Al, Poodt HD, Mulder CL. Effects of community-care networks on psychiatric emergency contacts, hospitalisation and involuntary admission. J Epidemiol Community Health 2007;61:613-8

55. Bailey A, McAllister A, McAuley W. The development of a protoco for the joint investigation of crimes committed against vulnerable adults. Tizard Learning Disability Review 2004;9:18-22.

56. Burton M, Evans R, Sanders A. Are special measures for vulnerable \& intimidated witnesses working? Evidence from the criminal justice agencies. London: Home Office, 2006.

57. Cambridge P, Parkes T. The Management and Practice of Joint Adult Protection Investigations between Health and Social Services: Issues Arising from a Training Intervention. Social Work Education 2006;25:824-37.

58. Donnelly M, McGilloway S. Mental illness in the UK criminal justice system: a police liaison scheme for mentally disordered offenders in Belfast. J Ment Health 2004;13:263-75.

59. Durcan D. Keys to diversion: Best practice for offenders with multiple needs. London: Centre for Mental Health, 2014. https:// www.centreformentalhealth.org.uk/keys-to-diversion.

60. Earl F, Cocksedge K, Rheeder B, et al. Neighbourhood outreach: a novel approach to Liaison and Diversion. $J$ Forens Psychiatry Psychol 2015;26:573-85.

61. Edmondson D, Cummins I. Oldham Mental Health Phone Triage/ RAID Pilot Project Evaluation Report. Manchester: Manchester Metropolitan University, 2014. http://www.crisiscareconcordat.org. uk/wp-content/uploads/2015/01/OLDHAMMH TRIAGE-2.pdf.

62. Etherington D. The Police Liaison Community Psychiatric Nurse Project. Mental Health Review Journal 1996;1:21-4.

63. Exworthy T, Parrott J. Comparative evaluation of a diversion from custody scheme. The Journal of Forensic Psychiatry 1997:8:406-16. 
64. Finn W, Hyslop J, Truman C. Mental health, multiple needs and the police: findings from the Revolving Doors Agency link worker scheme. London: Revolving Doors, 2000.

65. Fyson R. Young people with learning disabilities who sexually harm others: the role of criminal justice within a multi-agency response. Br J Learn Disabil 2007;35:181-6.

66. Gibson S, Hamilton S KJ. Evaluation of the Crisis Care Concordat implementation Final Report. London: McPin Foundation for Mind, 2016. http://mcpin.org/wp-content/uploads/CCC-Evaluation Report.pdf.

67. Great Britain Home Office. Alternative place of safety: the West Sussex pilot evaluation 2015. London: Great Britain: Home Office, 2015.

68. Heslin M, Callaghan L, Packwood M, et al. Decision analytic model exploring the cost and cost-offset implications of street triage. BMJ Open 2016;6:e009670.

69. Hollingsworth N. A fair hearing. Nurs Times 2000;96:41-2.

70. Irvine A, Allen L, Webber M. Evaluation of the Scarborough, Whitby and Ryedale Street Triage Service. York: University of York, 2015.

71. James DV, Harlow P. Increasing the power of psychiatric court diversion: a new model of supra-district diversion centre. Med Sci Law 2000;40:52-60.

72. James D, Cripps J, Gilluley P, et al. A court-focused model of forensic psychiatry provision to central London: Abolishing remands to prison? The Journal of Forensic Psychiatry 1997;8:390-405.

73. James D. Police station diversion schemes: role and efficacy in central London. The Journal of Forensic Psychiatry 2000;11:532-55.

74. James DV, Kerrigan TR, Forfar R, et al. The Fixated Threat Assessment Centre: preventing harm and facilitating care. J Forens Psychiatry Psychol 2010;21:521-36.

75. Kirkland J, Baron E. Using a cognitive analytic approach to formulate a complex sexual and violent offender to inform multiagency working: developing a shared understanding. J Sex Aggress 2015;21:394-405.

76. Lennox C, Mason J, McDonnell S, et al. Information sharing between the National Health Service and criminal justice system in the United Kingdom. J Forensic Nurs 2012;8:131-7.

77. Mann A, Sugarman P, Rooney C, et al. Service innovation: policing mental health - the St Andrew's scheme. Psychiatr Bull 2007:31:97-8

78. Marlow K. Achieving best evidence.. LLais Magazine 2003;68:3-5.

79. McAllister A, Bailey A, Barr O. Training in joint investigation of alleged crimes against people with learning disabilities in Northern Ireland. The Journal of Adult Protection 2002;4:21-7.

80. McGilloway S, Donnelly M. Mental illness in the UK criminal justice system: A police liaison scheme for Mentally Disordered Offenders in Belfast. J Ment Health 2004;13:263-75.

81. McLean N, Marshall LA. A front line police perspective of mental health issues and services. Crim Behav Ment Health 2010;20:62-71.

82. Noga H, Foreman A, Walsh E, et al. Multi-agency action learning: Challenging institutional barriers in policing and mental health services. Action Res 2016;14:132-50.

83. Pakes F, Winstone J. A site visit survey of 101 mental health liaison and diversion schemes in England. J Forens Psychiatry Psychol 2010;21:873-86.

84. Penny C, Craissati J. Decisions on disclosure to third parties made at MAPP meetings: opinions and practice. Psychiatrist 2012;36:379-85.

85. Riordan S, Wix S, Kenney-Herbert J, et al. Diversion at the point of arrest: mentally disordered people and contact with the police. The Journal of Forensic Psychiatry 2000;11:683-90.

86. Riordan S, Wix S, Haque MS, et al. Multiple contacts with diversion at the point of arrest. Med Sci Law 2003;43:105-10.

87. Rowlands R, Inch H, Rodger W, et al. Diverted to where? What happens to the diverted mentally disordered offender. The Journal of Forensic Psychiatry 1996;7:284-96.

88. Scott D, McGilloway S, Donnelly M. A prospective comparative evaluation of a Criminal Justice Liaison and Diversion Service in Belfast. J Forens Psychiatry Psychol 2016;27:198-214.

89. Thames Valley Police. Oxfordshire Mental Health Street Triage Pilot. Oxfordshire, 2015.

90. Vaughan PJ, Kelly M, Pullen N. The working practices of the police in relation to mentally disordered offenders and diversion services. Med Sci Law 2001;41:13-20.

91. Wain N. May the force be with you. Community Care 2000;31:22-3.

92. Barrett JG, Janopaul-Naylor E. Description of a collaborative community approach to impacting juvenile arrests. Psychol Serv 2016;13:133-9.

93. Bonkiewicz L, M. Green A, Moyer K, et al. Left alone when the cops go home: evaluating a post-mental health crisis assistance program. Policing: An International Journal of Police Strategies \& Management 2014;37:762-78.

94. Borum R, Deane MW, Steadman HJ, et al. Police perspectives on responding to mentally ill people in crisis: perceptions of program effectiveness. Behav Sci Law 1998;16:393-405.

95. Bracey JR, Foley Geib C, Plant R, et al. Connecticut's Comprehensive Approach to Reducing In-School Arrests: Changes in Statewide Policy, Systems Coordination and School Practices. Fam Court Rev 2013;51:427-34.

96. Clayfield JC, Grudzinskas JAJ, Fisher WH, et al. E pluribus unum: creating a multi-organizational structure for serving arrestees with serious mental illness. Research in Social Problems \& Public Policy 2005;12:27-49.

97. Coggins MH, Pynchon MR. Mental health consultant to law enforcement: Secret Service development of a Mental Health Liaison Program. Behav Sci Law 1998;16:407-22.

98. Compton MT, Broussard B, Hankerson-Dyson D, et al. Systemand Policy-Level Challenges to Full Implementation of the Crisis Intervention Team (CIT) Model. J Police Crisis Negot 2010;10:72-85

99. Crutcher KD. The Early Notification Program. FBI Law Enforcement Bulletin 2011;80:12-15.

100. Deane MW, Steadman HJ, Borum R, et al. Emerging partnerships between mental health and law enforcement. Psychiatr Serv 1999;50:99-101.

101. DeCuir W, Lamb R. Police response to the dangerous mentally ill. The Police Chief 1996:99-106.

102. Dupont R, Cochran S, Pillsbury S. Crisis Intervention Team core elements. Memphis: The University of Memphis School of Urban Affairs and Public Policy, Dept. of Criminology and Criminal Justice, CIT Center, 2007.

103. el-Mallakh RS, Wulfman G, Smock W, et al. Implementation of a crisis intervention program for police response to mental health emergencies in Louisville. J Ky Med Assoc 2003;101:241-3.

104. Frank J, Eck J, Ratansi S. Mobile crisis team/police collaboration evaluation. Cincinnati: University of Cincinnati, 2004

105. Geller JL, Fisher WH, McDermeit M. A national survey of mobile crisis services and their evaluation. Psychiatr Serv 1995;46:893-7.

106. Gordon $C$, Chabot L. Jail diversion program shows power of teamwork. Behav Healthc Tomorrow 2004;13:31-5.

107. Grudzinskas AJ, Clayfield JC, Roy-Bujnowski K, et al. Integrating the criminal justice system into mental health service delivery: the worcester diversion experience. Behav Sci Law 2005;23:277-93.

108. Hails J, Borum R. Police training and specialized approaches to respond to people with mental illnesses. Crime \& Delinquency 2003;49:52-61.

109. Hamilton ZK, Sullivan CJ, Veysey BM, et al. Diverting multiproblem youth from juvenile justice: investigating the importance of community influence on placement and recidivism. Behav Sci Law 2007;25:137-58.

110. Hartford K, Carey R, Mendonca J. Pre-arrest diversion of people with mental illness: Literature review and international survey. Behav Sci Law 2006;24:845-56.

111. Hatcher $\mathrm{C}$, Mohandie K, Turner $\mathrm{J}$, et al. The role of the psychologist in crisis/hostage negotiations. Behav Sci Law 1998;16:455-72.

112. Helfgott JB, Hickman MJ, Labossiere AP. A descriptive evaluation of the Seattle Police Department's crisis response team officer/mental health professional partnership pilot program. Int J Law Psychiatry 2016;44:109-22.

113. Hill R, Quill G, Ellis K. The Montgomery County CIT model: Interacting with people with mental illness. FBI Law Enforcement Bulletin 2004;73:18-25.

114. Hoff RA, Baranosky MV, Buchanan J, et al. The effects of a jail diversion program on incarceration: a retrospective cohort study. $J$ Am Acad Psychiatry Law 1999;27:377-86.

115. James RK, Logan J, Davis SA. Including School Resource Officers in school-based crisis intervention: Strengthening student support. Sch Psychol Int 2011;32:210-24.

116. Janofsky JS, Tamburello AC. Diversion to the mental health system: emergency psychiatric evaluations. J Am Acad Psychiatry Law 2006;34:283-91.

117. Klein M. Law Enforcement's Response to People with Mental Illness. FBI Law Enforcement Bulletin 2002;71:11

118. Lacey $\mathrm{CH}$. Collaborative Partnerships and School Change: Evaluating Project SOBEIT: Online Submission: ERIC, 2006.

119. Lamb HR, Shaner R, Elliott DM, et al. Outcome for psychiatric emergency patients seen by an outreach police--mental health team. New Dir Ment Health Serv 2001;1995:67-76.

120. Lattimore PK, Broner N, Sherman R, et al. A Comparison of Prebooking and Postbooking Diversion Programs for Mentally III Substance-Using Individuals With Justice Involvement. Journal of Contemporary Criminal Justice 2003;19:30-64. 
121. Lord VB, Bjerregaard B. Helping Persons with Mental Illness: Partnerships between Police and Mobile Crisis Units. Vict Offender 2014;9:455-74.

122. Marans S, Berkowitz SJ, Cohen DJ. Police and mental health professionals. Collaborative responses to the impact of violence on children and families. Child Adolesc Psychiatr Clin N Am 1998;7:635-51.

123. McGuire AB, Bond GR. Critical elements of the crisis intervention team model of jail diversion: an expert survey. Behav Sci Law 2011;29:81-94.

124. Murphy RA, Rosenheck RA, Berkowitz SJ, et al. Acute service delivery in a police-mental health program for children exposed to violence and trauma. Psychiatr Q 2005;76:107-21.

125. Oliva JR, Compton MT. A statewide Crisis Intervention Team (CIT) initiative: evolution of the Georgia CIT program. J Am Acad Psychiatry Law 2008;36:38-46.

126. Perez A, Leifman S, Estrada A. Reversing the criminalization of mental illness. Crime \& Delinquency 2003;49:62-78.

127. Project Link DoP. Gold Award: prevention of jail and hospita recidivism among persons with severe mental illness. Psychiatr Serv 1999:50:1477-80.

128. Rosenbaum N. Street-Level Psychiatry-A Psychiatrist's Role with the Albuquerque Police Department's Crisis Outreach and Support Team. Journal of Police Crisis Negotiations 2010;10:175-81.

129. Saunders JEG. Missing and Wandering Children with Autism and Down Syndrome: The Project Lifesaver Partnership Meets the Challenge. Sheriff 2006;58:26-8.

130. Scott RL. Evaluation of a mobile crisis program: effectiveness, efficiency, and consumer satisfaction. Psychiatr Serv 2000;51:1153-6.

131. Shafer MS, Arthur B, Franczak MJ. An analysis of post-booking jail diversion programming for persons with co-occurring disorders. Behav Sci Law 2004;22:771-85.

132. Skubby D, Bonfine N, Novisky M, et al. Crisis Intervention Team (CIT) programs in rural communities: a focus group study. Community Ment Health J 2013;49:756-64.

133. Steadman HJ, Deane MW, Morrissey JP, et al. A SAMHSA research initiative assessing the effectiveness of jail diversion programs for mentally ill persons. Psychiatr Serv 1999;50:1620-3.

134. Steadman HJ, Naples M. Assessing the effectiveness of jail diversion programs for persons with serious mental illness and cooccurring substance use disorders. Behav Sci Law 2005;23:163-70.

135. Swartz MS, Swanson JW, Kim M, et al. Use of outpatient commitment or related civil court treatment orders in five U.S. communities. Psychiatr Serv 2006;57:343-9.

136. Teske SC. A study of zero tolerance policies in schools: a multiintegrated systems approach to improve outcomes for adolescents. J Child Adolesc Psychiatr Nurs 2011;24:88-97.

137. Teller JL, Munetz MR, Gil KM, et al. Crisis intervention team training for police officers responding to mental disturbance calls. Psychiatr Serv 2006;57:232-7.

138. Trupin EW, Selby PM, McCauley E, et al. The Prime Time Project: Developing an Intensive Community-Based Intervention for Youth in the Juvenile Justice System. Dublin', Ohio, US: WorldCat member library, 1996.

139. Van Hasselt VB, Killam G, Schlessinger KM, et al. The Adolescent Drug Abuse Prevention and Treatment (ADAPT) Program: A Mental Health-Law Enforcement Collaboration. J Child Adolesc Subst Abuse 2006;15:87-104.

140. Wolff N. Interactions between mental health and law enforcement systems: problems and prospects for cooperation. $J$ Health Polit Policy Law 1998;23:133-74.

141. Wood JD, Beierschmitt L. Beyond police crisis intervention: moving "upstream" to manage cases and places of behavioral health vulnerability. Int J Law Psychiatry 2014;37:439-47.

142. Meehan AJ. From conversion to coercion: the police role in medication compliance. Psychiatr Q 1995;66:163-84.

143. Sharp CR. Theoretical and Practical Application of Loose Coupling: A Study of Criminal Justice Agencies in the State of Florida. SWJCJ 2009;6:45-58.
144. Steadman HJ, Deane MW, Borum R, et al. Comparing outcomes of major models of police responses to mental health emergencies. Psychiatr Serv 2000;51:645-9.

145. Wellborn. Responding to individuals with mental illness. FBI Law Enforcement Bulletin 1999;68:6.

146. Rollison J, Hill G, Yu P, et al. Evaluation of a complex, multisite, multilevel grants initiative. Eval Program Plann 2012;35:273-9.

147. Wolff N, Frueh BC, Huening J, et al. Practice informs the next generation of behavioral health and criminal justice interventions. Int J Law Psychiatry 2013;36:1-10.

148. Wolff N, Diamond RJ, Helminiak TW. A new look at an old issue: people with mental illness and the law enforcement system. $J$ Ment Health Adm 1997;24:152-65.

149. Crisp AP. Understanding Best Practice: The Emergency Response to Mental IIIness-An Exploratory Report. London: Winston Churchill Memorial Trust, 2015.

150. Ligon JAN, Thyer BA. Client and family satisfaction with brief community mental health, substance abuse, and mobile crisis services in an urban setting. Crisis Intervention and Time-Limited Treatment 2000;6:93-9.

151. Durcan G. The Bradley report five years on: an independent review of progress to date and priorities for further development. London: Centre for Mental Health, 2014.

152. Department of Health. Mental Health Act 1983: Code of Practice. Norwich: The Stationery Office, 2015.

153. College of Policing. Statistical data. $2017 \mathrm{https} / / /$ data.police.uk/ data/statistical-data/ (accessed 14 July 2017).

154. O'Mara-Eves A, Brunton G, McDaid D, et al. Techniques for identifying cross-disciplinary and 'hard-to-detect' evidence for systematic review. Res Synth Methods 2014;5:50-9.

155. Macvean M, Humphreys C, Healey L, et al. The PATRICIA Project: PAThways and Research in Collaborative Inter-Agency working: State of knowledge paper Sydney. Australia: ANROWS Landscapes, 2015.

156. Munetz MR, Griffin PA. Use of the Sequential Intercept Model as an approach to decriminalization of people with serious mental illness. Psychiatr Serv 2006;57:544-9.

157. Charette Y, Crocker AG, Billette I. Police encounters involving citizens with mental illness: use of resources and outcomes. Psychiatr Serv 2014;65:511-6.

158. McManus S, Meltzer H, Brugha T, et al. Adult psychiatric morbidity in England 2007: results of a household survey. London: The NHS Information Centre for health and social care, 2009.

159. Craig P, Dieppe P, Macintyre S, et al. Medical Research Council Guidance. Developing and evaluating complex interventions: the new Medical Research Council guidance. BMJ 2008;337:a1655.

160. Department of Health and Concordat signatories. Mental Health Crisis Care Concordat: Improving outcomes for people experiencing mental health crisis. London: HM Government, 2014.

161. UK Crown. Policing and Crime Act 2017. London: The Stationery Office, 2017.

162. Kane E, Evans E, Shokraneh F. Effectiveness of current policingrelated mental health interventions in England and Wales and Crisis Intervention Teams as a future potential model: a systematic review. Syst Rev 2017;6:85.

163. Innes M. A 'Mirror' and a 'Motor': Researching and Reforming Policing in an Age of Austerity. Policing 2010;4:127-34.

164. Valentijn PP, Schepman SM, Opheij W, et al. Understanding integrated care: a comprehensive conceptual framework based on the integrative functions of primary care. Int $J$ Integr Care 2013;13:e010.

165. Moore GF, Audrey S, Barker M, et al. Process evaluation of complex interventions: Medical Research Council guidance. BMJ 2015;350:h1258.

166. Moher D, Liberati A, Tetzlaff J, et al. Preferred reporting items for systematic reviews and meta-analyses: the PRISMA statement. PLoS Med 2009;6:e1000097.

167. Steadman HJ, Cocozza JJ, Veysey BM. Comparing outcomes for diverted and nondiverted jail detainees with mental illnesses. Law Hum Behav 1999;23:615-27. 